\title{
A POLISSEMIA dO TERMO "ÁREA PROTEGIDA" E OS CONCEITOS DA CDB E DA UICN
}

\author{
André O. Leite ${ }^{1}$ \\ Vilniaus Universitetas (VU)
}

\section{RESUMO}

Partindo de uma demonstração da polissemia que caracteriza o uso do termo "área protegida" na jurisprudência e na literatura científica brasileiras sobre a proteção do ambiente natural, este trabalho discute brevemente os problemas relacionados a esse fenômeno, no âmbito do direito e do campo multidisciplinar das políticas públicas de conservação, e busca oferecer elementos para sua superação. Com essa finalidade, ele apoia-se em uma revisão bibliográfica para discutir os conceitos de área protegida da Convenção sobre Diversidade Biológica $(\mathrm{CDB})$ e da União Internacional para a Conservação da Natureza (UICN), buscando distingui-los quanto a seus conteúdos e potenciais usos. Demonstra-se que os conteúdos atribuídos a esses conceitos conheceram modificações sucessivas e que, embora atualmente ambos compreendam as unidades de conservação da Lei n. 9.985, de 18 de julho de 2000, eles apresentam interesses distintos. Enquanto o conceito de área protegida da CDB concerne a atividade jurisdicional e análises sobre o direito e as políticas públicas brasileiras relacionadas à $\mathrm{CDB}$, o conceito de área protegida da UICN é um instrumento científico e, como tertium comparationis dos regimes jurídicos de áreas protegidas dos direitos nacionais, permite operacionalizar pesquisas que buscam conhecelos por meio do método funcional do direito comparado.

Palavras-chave: áreas protegidas; Convenção sobre Diversidade Biológica; Direito comparado; UICN; unidades de conservação.

1 Doutor em Direito pelo Conservatoire National des Arts et Métiers (CNAM). Doutor em Direito pela Universidade Federal de Santa Catarina (UFSC). Membro da Comissão Mundial de Áreas Protegidas da União Internacional para a Conservação da Natureza (UICN). Membro da Société Française pour le Droit de L'Environnement (SFDE). Pesquisador Associado da Faculdade de Direito da VU. ORCID: https://orcid.org/0000-0002-9250-4753 / e-mail: andre_oleite@hotmail.com 


\section{THE POLYSEMY OF THE TERM "PROTECTED AREA" AND THE CORRESPONDING CBD AND IUCN CONCEPTS}

\section{ABSTRACT}

This paper draws on a demonstration of the polysemy of the term 'protected area' in Brazilian case law and literature on the protection of the natural environment, in order to discuss the problems stemming from this phenomenon and the possibilities for overcoming them. Based on a literature review, it introduces the Convention on Biological Diversity (CBD) and International Union for the Conservation of Nature (IUCN) concepts of protected area, and seeks to distinguish one from another by means of their contents and potential uses. It demonstrates that the contents attributed to those concepts have changed over time, and that recently both came to comprise the conservation units of Law No. 9,985, of 18 July 2000. Nevertheless, it shows those concepts are characterised by different natures and purposes: while the CBD concept of protected area is of interest to legal and policy research related to that treaty, the IUCN concept of protected area is a scientific instrument and a tertium comparationis of national legal regimes of protected areas. As such, it provides a framework for research based on the functional method of comparative law.

Keywords: Brazilian Conservation Units; Comparative law; Convention on Biological Diversity; IUCN; Protected areas. 


\section{INTRODUÇÃO}

Nas décadas recentes tornou-se trivial reconhecer o papel desempenhado pelas áreas protegidas no fornecimento de serviços ambientais que se traduzem em água e ar limpos (DUDLEY; HAMILTON, 2010, p. 39-52); na regulação do clima e consequentemente na atenuação da mudança climática global (KEENLEYSIDE et al., 2014, p. 67-78; SOARES-FILHO et al., 2010, p. 10821-10826); na conservação da natureza e, mais recentemente, da diversidade biológica (PRATES; IRVING, 2015, p. 27-57; SADELEER, 2009, p. 195-197); e, de maneira mais geral, na efetivação do direito fundamental a um meio ambiente de qualidade, atualmente reconhecido pela grande maioria das legislações nacionais (BOYD, 2012, p. 3). Sem surpresa, na segunda década do século XXI os dispositivos jurídicos de áreas protegidas se encontram presentes em praticamente todos os direitos nacionais (GILLESPIE, 2007, p. 27) e protegem 14,9\% da superfície terrestre mundial (uma área superior à do subcontinente da América do Norte) e 7,3\% dos oceanos (UNEP-WCMC; IUCN; NGS, 2018, p. 6) ${ }^{2}$.

A notável progressão espacial das áreas protegidas ao longo de sua história por vezes obscurece o fato de se tratar de um fenômeno recente (RODARY; MILIAN, 2008, p. 41), e que, em ampla medida, deu-se por meio da circulação de conceitos e modelos jurídicos, sobretudo por meio da recepção de conteúdos jurídicos estrangeiros e do direito internacional. E, seja pela adaptação de modelos estrangeiros às particularidades locais ou pela gradual integração de novos objetivos aos métodos tradicionais da conservação da natureza, os poucos modelos jurídicos de áreas protegidas existentes no início do século XX deram lugar a uma impressionante diversidade de nomenclaturas e regimes jurídicos ${ }^{3}$.

Historicamente, essa diversificação tem sido acompanhada por uma dificuldade em estabelecer uma terminologia capaz de dar conta da variedade de dispositivos presentes nos direitos nacionais

2 Esses números são da Base de Dados Mundial de Áreas Protegidas. Seus dados são majoritariamente provenientes de governos e correspondem ao conceito de área protegida da Convenção sobre Diversidade Biológica ou ao conceito de área protegida da UICN (UNEP-WCMC; IUCN; NGS, 2018, p. 3, 41).

3 Essa diversidade é ilustrada por Gillespie (2007, p. 27), que constatou, no âmbito dos direitos nacionais e do direito internacional, cerca de oitocentas nomenclaturas de instrumentos de proteção de áreas naturais. 
(PHILLIPS, 2004, p. 5-9) e por uma utilização crescente, mas nem sempre precisa, do termo "área protegida" para designá-los. A jurisprudência e a literatura brasileiras relativas ao direito e às políticas públicas ambientais não escapam a esse fenômeno, e permitem constatar uma pluralidade de conteúdos semânticos atribuídos a esse mesmo significante, evidenciando que área protegida é objeto de um fenômeno de polissemia ${ }^{4}$.

As implicações epistemológicas desse tipo de fenômeno no âmbito da pesquisa em direito têm sido objeto de estudos no campo da terminologia jurídica, que reiteram o papel desempenhado pela doutrina na precisão de conceitos jurídicos em sentido estrito e daqueles que permitem conhecer, a partir de uma perspectiva externa, o fenômeno jurídico e aspectos como sua estrutura, funcionamento e evolução (DÉAL, 2004, p. 237). E, na perspectiva mais ampla das ciências sociais e humanas, essa mesma questão foi estudada nos campos da filosofia da ciência e da epistemologia do conhecimento e é objeto de prescrições metodológicas que salientam a relação entre a precisão dos conceitos utilizados como unidades de análise e a validade do conhecimento científico produzido.

A constatação da polissemia nos usos do termo "área protegida" (1), portanto, convida a precisar os conceitos de área protegida que interessam à comunidade que pesquisa o direito e as políticas públicas de conservação da natureza, distinguindo-os por seus conteúdos e seus potenciais usos. Este trabalho se enquadra em um debate mais amplo a respeito das nomenclaturas e da comparabilidade dos regimes jurídicos de áreas protegidas, e contribui para essa temática ao tratar dos usos e conteúdos de dois conceitos de área protegida que podem permitir superar a polissemia que os caracteriza: o conceito de área protegida da Convenção sobre Diversidade Biológica (CDB), que é parte do direito objetivo e, portanto, importa à atividade jurisdicional e à ciência do direito (2), e o conceito de área protegida da União Internacional para a Conservação da Natureza (UICN), que possui caráter científico e permite estabelecer relações de equivalência funcional entre dispositivos jurídicos de diferentes ordenamentos, e, consequentemente, conhecê-los a partir do direito comparado (3).

4 A definição do escopo deste trabalho implicou afastar, intencionalmente, outros termos e conceitos que, potencialmente, podem se sobrepor à noção de área protegida e ser objeto de divergência quanto a seu conteúdo, como é o caso do conceito de espaços territoriais especialmente protegidos, do art. 225 da Constituição Federal. Sobre este, vide Ganem e Araújo (2006), Braga e Della Nina (2015) e Pereira e Scardua (2008). 


\section{A POLISSEMIA DO TERMO “ÁREA PROTEGIDA"}

Existem indícios de que a utilização do termo "área protegida" para designar uma classe específica de regimes jurídicos de proteção de zonas naturais, sobretudo em língua inglesa, remonta a finais do século XIX e foi se firmando no vocabulário científico à medida que esses regimes jurídicos se difundiam pelo mundo. ${ }^{5}$ Essa utilização adentrou a legislação brasileira antes mesmo da CDB, embora de maneira localizada, e, por essa época, já se encontrava consolidada no jargão da comunidade científica do País. ${ }^{6}$ Com a promulgação da $\mathrm{CDB}$ e a instituição do Plano Estratégico Nacional de Áreas Protegidas (PNAP), pelo Decreto n. 5.758, de 13 de abril de 2006, ela se difundiu nas fontes do direito e na literatura especializada.

Contudo, em consonância com seu uso anterior à promulgação da CDB e com um fenômeno também notado no âmbito de outros países e idiomas (PHILLIPS, 2004, p. 5-9), os sentidos atribuídos a esse termo permanecem variados e fazem referência a uma diversidade de regimes jurídicos de conservação in situ da natureza. Dito de outro modo, uma análise detida da utilização do termo "área protegida", em decisões judiciais e na literatura relacionadas à proteção do ambiente natural, mostra que ele é objeto de um fenômeno de polissemia.

Isso ocorre, em parte, porque diferentes conceitos de área protegida coexistem, nomeadamente aqueles da CDB e da UICN, e porque seus conteúdos têm variado ao longo do tempo. Mas, além deles, também é possível notar a utilização de uma noção menos científica de área protegida, isso é, mais próxima de seu sentido na linguagem comum. Isso, evidentemente, não equivale a dizer que seu uso é arbitrário, pois mesmo o conteúdo semântico comum do conjunto formado por área e protegida reflete a característica essencial de todo dispositivo jurídico de conservação in situ da

5 Como indicativo disso, uma pesquisa pelo termo "protected área" no Google Ngram Viewer, um mecanismo de pesquisa que mapeia as frequências com que palavras, termos e expressões aparecem em fontes impressas em idiomas específicos, mostra uma curva de utilização, em língua inglesa, que apresenta semelhança evidente com o levantamento da progressão geográfica dos regimes jurídicos de proteção dos espaços naturais apresentado por Rodary e Milian (2008, p. 41).

6 Existem numerosos exemplos do uso precursor do termo "área protegida" como sinônimo de zona destinada à pesquisa e conservação. Como ilustração de seu uso no âmbito científico, vide Magnanini (1971, p. 17), Bruck et al. (1983, p. 26), Ferreira e Valera (1987, p. 5, 11) e Gusmão Câmara (1991, p. 76). Como exemplo de seu uso na legislação brasileira, vide o Decreto n. 11.122, de 1988, do Distrito Federal. 
natureza: a territorialização da norma ambiental com fins de conservação ${ }^{7}$.

De fato, é possível argumentar que essa característica constitui o elemento fundamental de uma noção lato sensu de área protegida, que é encontrada com frequência em decisões de tribunais brasileiros, onde tem sido utilizada para designar pontualmente ${ }^{8}$ instrumentos jurídicos como as reservas legais (SÃO PAULO, 2015, 2016) e as áreas de preservação permanente (BRASIL, 2018, 2019b) do Código Florestal; as unidades de conservação da Lei n. 9.985, de 18 de julho de 2000 (BRASIL, 2009, 2014); as áreas tombadas com base no art. 216 da Constituição (PARÁ, 2013); e, ainda, categorias específicas previstas em planos diretores municipais (SÃO PAULO, 2010; RIO DE JANEIRO, 2019) e em legislações estaduais (SÃO PAULO, 2019).

Essa noção lato sensu também aparece com frequência na literatura relativa ao direito e às políticas públicas de conservação da natureza, invariavelmente incluindo as unidades de conservação. Contudo, diferentemente de seu uso em decisões judiciais, parte considerável de seu uso designa conjuntos de dispositivos heterogêneos que incluem as terras indígenas; reservas legais; áreas de preservação permanente; algumas das categorias provenientes do direito internacional, que não possuem escopo normativo e, portanto, por si não podem proteger as zonas sobre as quais incidem; e as já mencionadas unidades de conservação?.

A problemática resultante de conceitos polissêmicos tem sido tratada em um número de trabalhos no campo da terminologia jurídica, que mostram que, embora esse fenômeno possa ser considerado "uma das marcas essenciais da linguagem do direito" (CORNU, 1990, p. X-XI, tradução nossa), a transparência dessa linguagem tem papel fundamental na segurança jurídica e na validade do conhecimento jurídico. De um lado, o direito se

7 Sobre a territorialização da norma jurídica ambiental, isso é, a aplicação de regimes jurídicos protetivos a espaços específicos e a consequente produção de territórios, vide Jégouzo (2006, p. 121-126).

8 Existem exceções, como uma decisão que utiliza o termo "área protegida" como sinônimo de espaço territorial especialmente protegido do art. 225 da Constituição (SÃO PAULO, 2018).

9 Esses usos são numerosos e variados. A título ilustrativo, vide Medeiros (2004); Brito (2008); Oliveira (2010); Cruz (2015, p. 27); Braga e Della Nina (2015); Dias et al. (2018); e Souza, Leal e Maciel (2019). Essas utilizações do termo "área protegida" muitas vezes mostram-se arbitrárias, no sentido de incluir nessa categoria determinados instrumentos, enquanto outros instrumentos de mesma natureza são deixados de fora. Isso é particularmente claro quanto às numerosas categorias provenientes do direito internacional. 
caracteriza por uma racionalidade particularmente dependente da separação, categorização e sistematização de objetos com o objetivo de lhes atribuir significado, e, assim, a atividade jurisdicional envolve demonstrações e enunciações que são articuladas por meio de categorias lógicas e expressas por meio da linguagem (GINSBURG; STEPHANOPOULOS, 2017; BAJČIĆ, 2017, p. 1625). A praticabilidade do direito, portanto, "depende especialmente da praticabilidade da sua linguagem" (BARRAUD, 2016, p. 6, trad. nossa). De outro lado, essa questão importa à validade do conhecimento, pois enunciados que incluem termos polissêmicos apresentam menor cientificidade do que aqueles inequívocos. Como o direito é uma "ciência verbal que estuda conjuntos verbais por meio de outros conjuntos verbais" (BARRAUD, 2016, p. 3, trad. nossa), a validade do conhecimento jurídico depende intensamente da precisão dos termos empregados (BARRAUD, 2016, p. 8-10; GUTTERIDGE, 1938, p. 411-413).

Ademais, a problemática resultante de conceitos polissêmicos ultrapassa o âmbito da ciência do direito e concerne a produção do conhecimento científico em geral. Um quadro conceitual unificado apresenta vantagens evidentes em termos de cientificidade, comunicabilidade e clareza, e que podem ser potencializadas em campos multidisciplinares como o das políticas públicas de conservação da natureza (GILLESPIE, 2007, p. 29). As seções seguintes deste trabalho buscam oferecer subsídios para que a polissemia desse termo possa ser superada, ao tratar de dois conceitos que interessam ao direito e às políticas públicas de conservação da natureza: primeiro o conceito de área protegida da $C D B$, de caráter jurídico em sentido estrito (2), e, em seguida, o conceito de área protegida da UICN, que expressa o consenso de grande parte da comunidade científica internacional (3).

\section{O CONCEITO DE ÁREA PROTEGIDA DA CONVENÇÃO SOBRE DIVERSIDADE BIOLÓGICA}

Embora a CDB não tenha inaugurado o engajamento externo brasileiro em proteger territórios portadores de um patrimônio natural importante e figure entre outros programas e tratados internacionais desse tipo dos quais o Brasil é parte, ela é amplamente 
reconhecida como o principal documento de direito internacional a tratar da conservação da natureza, sobretudo por conta da adesão que foi capaz de angariar junto à comunidade internacional e de sua ambição, visto que estabelece um quadro apropriado para que metas crescentes sejam negociadas nos sucessivos encontros de sua Conferência das Partes (COP).

Por meio da CDB, os Estados-partes buscaram estabelecer uma estrutura conceitual comum para proteção da biodiversidade, e que se traduz em uma pluralidade de definições, entre as quais a de área protegida. Essa definição, evidentemente, inclui um número de elementos que compõem o conceito de área protegida da $\mathrm{CDB}$, e dos quais teremos ocasião de tratar. Contudo, antes de adentrar a questão de seu conteúdo (2.2), cabem alguns comentários quanto à sua natureza e à natureza desse conteúdo (2.1).

\subsection{Um conceito jurídico}

$\mathrm{O}$ conceito de área protegida da $\mathrm{CDB}$ possui um caráter jurídico evidente, pois, ao ser assinada, ratificada e eventualmente promulgada, a Convenção e seus conceitos adentraram o direito internacional e os direitos nacionais. Enquanto norma jurídica, sob o ponto de vista formal esse conceito integra um sistema de regras para solução de conflitos e tomada de decisões. Entretanto, por conta de sua origem no direito internacional, ele apresenta algumas peculiaridades em relação a outros conceitos do direito interno.

Primeiro, a definição de área protegida da $\mathrm{CDB}$, como o restante do direito internacional, foi elaborada com deferência ao princípio Pacta sunt servanda, e, portanto, com base na vontade das Partes da CDB. Isso equivale a dizer que essa definição foi produzida no curso de um processo próprio ao direito internacional, que envolve a negociação entre as Partes com vistas a assegurar sua adesão. Embora seja verdade que a iniciativa para elaboração da Convenção tenha pertencido a organismos da sociedade civil, e que suas etapas iniciais de elaboração tenham envolvido a participação de organismos científicos, seu conteúdo, incluindo sua definição de área protegida, resulta essencialmente da vontade de governos 
nacionais e exprime seu consenso ${ }^{10}$. Naturalmente, esses Estadospartes buscaram negociar seu conteúdo de maneira a compreender uma série de medidas que já vinham levando a cabo, resultando em um conceito relativamente simples e que permite certa flexibilidade em sua interpretação.

E, em segundo lugar, também por conta de sua origem internacional, cabem às Partes definir a relação entre esse conceito e os dispositivos de seus direitos internos. Contudo, a CDB é uma convenção-quadro e as reuniões de sua COP continuam a negociar novos compromissos, incluindo crescentes metas de criação de áreas protegidas, e, assim, os Estados-partes podem escolher não definir taxativamente, sobretudo por meio de lei, o escopo exato desse conceito em relação a seus direitos internos. Como se verá mais adiante, ambas questões têm levado a dificuldades na identificação das áreas protegidas do direito brasileiro.

\subsection{Conteúdo no direito brasileiro}

$\mathrm{O}$ art. $2^{\circ}$ da $\mathrm{CDB}$ conceitua área protegida como “área definida geograficamente que é destinada, ou regulamentada, e administrada para alcançar objetivos específicos de conservação" (BRASIL, 1998a). Essa definição inclui precisamente três critérios, nomeadamente a territorialização da regra de direito, a previsão de objetivos específicos de conservação e uma gestão ativa buscando realizar esses objetivos específicos.

Quando da promulgação da CDB, o direito brasileiro contava com uma pluralidade de instrumentos de conservação in situ, e também alguns conceitos que agrupavam diversos desses instrumentos e poderiam se sobrepor ao conceito de área protegida da CDB. Naturalmente, a recepção desse conceito no direito interno encorajou um debate a seu respeito, mas desdobramentos nos antes

10 As origens da CDB podem ser traçadas até a 15a Assembleia Geral da UICN, em 1981 (DE KLEMM, 1982, p. 120). Sobre a tramitação dessa proposta no interior da UICN, vide Cyrille de Klemm (1993, p. 17-19). Uma vez no âmbito das Nações Unidas, a futura convenção foi debatida em três reuniões do Grupo de trabalho ad hoc de especialistas em diversidade biológica, entre novembro de 1988 e julho de 1990, e em três reuniões do Grupo de trabalho ad hoc de especialistas jurídicos e técnicos em diversidade biológica, entre novembro de 1990 e o início de julho de 1991. A última reunião dos especialistas jurídicos e técnicos, realizada em Madri, coincidiu com a primeira reunião do Comitê Intergovernamental de Negociação para uma Convenção sobre Diversidade Biológica, que, na realidade, foi a terceira sessão de negociação entre os Estados-partes. No total, ocorreram sete reuniões de negociação. Seu texto foi aprovado durante uma conferência em maio de 1992 (CBD, 2020). 
seguintes levaram a uma diversidade de interpretações na literatura especializada e na documentação relativa à Convenção.

Dito de outro modo, em uma perspectiva cronológica o conceito de área protegida da CDB é, ele mesmo, polissêmico. Como esse conceito possui implicações tanto no direito interno (2.2.1) quanto no direito internacional (2.2.2), e o conteúdo que lhe é atribuído resulta de um diálogo entre essas instâncias, faz-se necessário investigar os conteúdos que lhe têm sido atribuído em ambos os casos e os desdobramentos que levaram a modificações em sua interpretação. Isso permitirá buscar superar essa polissemia, isso é, identificar o conteúdo ou os possíveis conteúdos desse conceito e as condições para seu uso arrazoado (2.2.3).

\subsubsection{Sua evolução nas fontes do direito interno}

Dada sua importância no âmbito do direito e das políticas públicas de conservação da natureza, é natural que muitos autores tenham tratado, diretamente ou indiretamente, do conceito de área protegida da CDB. É preciso reconhecer, contudo, que o debate a seu respeito permanece pouco pronunciado, sobretudo em razão da flexibilidade desse conceito no âmbito das obrigações internacionais assumidas pelo Brasil e da natureza do conteúdo do PNAP, que se restringe a declarar objetivos e estabelecer princípios e diretrizes. Por esse mesmo motivo, o juiz brasileiro raramente tem tido oportunidade de contribuir para este debate ${ }^{11}$.

Duas interpretações distintas do conceito de área protegida da CDB são mais comumente identificáveis na doutrina e, de modo mais geral, na literatura especializada. Em primeiro lugar, para um grupo de autores as áreas protegidas da CDB se restringiriam unicamente às unidades de conservação da Lei n. 9.985, de 18 de julho de 2000, dita Lei do SNUC (RIOS, 2004, p. 78; SANTILLI, 2005, p. 78-81; GANEM; ARAÚJO, 2006, p. 73; FIGUEIREDO, 2015, p. 15). E, em segundo lugar, para outros autores o conceito de área protegida da CDB incluiria, além das unidades de conservação, as terras indígenas e as terras ocupadas por remanescentes das comunidades dos quilombos (LEUZINGER, 2007, p. 122; PEREIRA; SCARDUA,

11 Decisões envolvendo o PNAP aparentam referir-se unicamente a unidades de conservação, por exemplo o Parque Nacional do Iguaçu (BRASIL, 2013b). 
2008, p. 85; ABI-EÇAB, 2011, p. 2; PRATES; IRVING, 2015, p. 41, 44; ASSUNÇÃO, 2016, p. 282). Por razões que se tornarão evidentes ao longo deste trabalho, essas interpretações devem ser consideradas em uma perspectiva cronológica.

Embora apenas ocasionalmente sejam apresentados argumentos detalhados justificando a atribuição desses conteúdos, em geral essas duas correntes priorizam questões distintas em suas interpretações. A primeira delas, que atribui um conteúdo mais restrito ao conceito de área protegida da $\mathrm{CDB}$, tende a salientar o conteúdo do termo "área protegida" no meio científico, isso é, seu sentido técnico no campo pluridisciplinar da conservação da natureza. Essa interpretação foi particularmente difundida até a edição do Decreto do PNAP, que trouxe novos elementos para este debate, mas tem conhecido um uso mais recente. $\mathrm{E}$ a segunda dessas correntes, que atribui ao conceito de área protegida da CDB um sentido mais amplo, invariavelmente faz referência ao Decreto do PNAP.

Essa última corrente vai ao encontro da Resolução CONABIO n. 3, de 21 de dezembro de 2006, que dispõe sobre as Metas Nacionais de Biodiversidade para 2010, correspondentes às metas globais do Plano Estratégico da CDB para 2010 (Decisão VI/26 da COP 6). Sua meta n. 2.2, relacionada à "promoção da conservação da diversidade biológica dos ecossistemas, habitats e biomas", trata especificamente das "Unidades do SNUC, Terras Indígenas e Territórios Quilombolas" (BRASIL, 2006a). Além disso, ela condiz com a opinião do próprio proponente do PNAP, o Ministério do Meio Ambiente. Na sequência da instituição do Plano, esse organismo publicou um documento que afirma que o PNAP "enfoca prioritariamente" as unidades de conservação, as terras indígenas e as terras ocupadas por remanescentes das comunidades quilombolas (BRASIL, 2006b, p. 38), e, portanto, sugere que esses são instrumentos de áreas protegidas da CDB.

A edição do decreto regulamentar que institui o PNAP, em 2006, de fato ofereceu ao Poder Executivo brasileiro uma boa oportunidade para que lançasse luz sobre o escopo desse conceito no direito brasileiro, e, portanto, sobre sua relação com os instrumentos de conservação in situ existentes. Contudo, o Decreto ou o Plano jamais abordam diretamente essa questão, e, além do mais, este último é ambíguo ao referir-se às áreas protegidas. 
Em primeiro lugar, o capítulo inicial do PNAP, que trata de seus princípios e diretrizes, indica múltiplas vezes que as áreas protegidas compreenderiam as unidades de conservação e também outros instrumentos ${ }^{12}$. Em seguida, esse mesmo capítulo parece excluir do rol das áreas protegidas as áreas de preservação permanente e as reservas legais do Código Florestal, considerando-as elementos integradores da paisagem ${ }^{13}$, e também as terras indígenas e as terras ocupadas por remanescentes das comunidades dos quilombos ${ }^{14}$. A julgar por esses princípios e diretrizes, o conceito de área protegida da CDB incluiria as unidades de conservação e ao menos algum outro dispositivo jurídico, mas não as áreas de preservação permanente, as reservas legais, as terras indígenas ou as terras ocupadas por remanescentes das comunidades dos quilombos.

Contudo, os capítulos seguintes do PNAP, que definem objetivos e estratégias para as áreas protegidas e os eixos temáticos em torno dos quais eles são organizados, contrariam essa interpretação. Primeiro, o capítulo "Dos Eixos Temáticos" e os dois capítulos seguintes, que contêm "Objetivos Gerais, Objetivos Específicos e Estratégias", dispõem expressamente a respeito do Sistema Nacional de Unidades de Conservação da Natureza (SNUC), das terras indígenas e das terras ocupadas por remanescentes das comunidades dos quilombos. E, em segundo lugar, o capítulo final, "Das Estratégias Nacionais para as Áreas com Reconhecimento Internacional", estabelece objetivos e estratégias para as "áreas de reconhecimento internacional" (BRASIL, 2006c, anexo, itens $2 ; 3-7 ; 8)$. Esses capítulos do PNAP, portanto, contradizem seus princípios e diretrizes, e indicam que o conceito de área protegida da CDB incluiria o SNUC, as terras indígenas e as terras ocupadas por remanescentes das comunidades dos quilombos, e, possivelmente,

12 "Valorização da importância e da complementariedade de todas as categorias de unidades de conservação e demais áreas protegidas [...]" (item 1.1, VIII); o "reconhecimento da importância da consolidação territorial das unidades de conservação e demais áreas protegidas" (item 1.1, XXIII); "facilitar o fluxo gênico entre as unidades de conservação, outras áreas protegidas e suas áreas de interstício" (item 1.2, VII); e "o planejamento para o estabelecimento de novas unidades de conservação, bem como para a sua gestão específica e colaborativa com as demais áreas protegidas [...]" (item 1.2, VIII) (BRASIL, 2006c, anexo, destaque nosso).

$13 \mathrm{O}$ "reconhecimento dos elementos integradores da paisagem, em especial as áreas de preservação permanente e as reservas legais, como fundamentais na conservação da biodiversidade" (BRASIL, 2006c, anexo, item 1.1, XI, destaque nosso).

14 A “articulação das ações de gestão das áreas protegidas, das terras indígenas e terras ocupadas por remanescentes das comunidades dos quilombos com as políticas públicas [...]" (BRASIL, 2006c, anexo, item 1.1, XIX, destaque nosso). 
as mencionadas "áreas de reconhecimento internacional”.

Além do mais, essas disposições levantam algumas questões. Primeiro, a despeito do conteúdo dos arts. 7, 8 e 14 da Lei n. 9.985, de 18 de julho de 2000, e por conta de seu art. 41, uma corrente doutrinária minoritária, mas digna de nota, considera as reservas da biosfera parte do SNUC, em conjunto com as doze categorias de unidades de conservação "de Uso Sustentável" e "de Proteção Integral". Assim, mesmo que se entenda que o conceito de área protegida da CDB inclui apenas o SNUC, por essa linha de raciocínio as reservas da biosfera também estariam incluídas. E, em segundo lugar, as áreas "de reconhecimento internacional" merecem considerações adicionais pois esse "reconhecimento" é posterior à sua afetação. Dito de outro modo, esse reconhecimento não produz efeitos jurídicos em termos de proteção das zonas sobre as quais incide, e, portanto, não há que se falar dele como instrumento de criação de áreas protegidas. Contudo, tipicamente essas áreas "de reconhecimento internacional" são compostas de unidades de conservação e, teoricamente, também podem ser constituídas por zonas protegidas por outros dispositivos, como o tombamento, do Decreto-lei n. 25, de 30 de novembro de 1937. Nesses casos excepcionais, portanto, esses outros instrumentos, por causa de uma utilização específica, poderiam servir como instrumentos de áreas protegidas da CDB.

Dadas essas questões a respeito do conteúdo do PNAP e a existência de uma divisão na literatura especializada, convém investigar o uso do conceito de área protegida na esfera dos compromissos brasileiros junto à CDB. Essa análise permitirá mostrar que o conteúdo atribuído a ele tem respondido a novos desdobramentos no direito interno e no direito internacional.

\subsubsection{Sua evolução no âmbito da $C D B$ e o conceito de outras medidas eficazes de conservação baseadas em áreas}

Os Estados-partes se comprometeram a apresentar periodicamente informações sobre as medidas adotadas para a implementação da CDB, e até este momento o governo brasileiro submeteu seis relatórios desse tipo ao Secretariado da Convenção. Esses documentos fornecem indiretamente informações sobre o 
escopo do conceito de área protegida, em suas seções relativas à cobertura espacial das áreas protegidas brasileiras. Como calcular esses dados de cobertura é um processo particularmente laborioso e que implica precisão metodológica e a disponibilidade de dados, esses documentos citam apenas os dispositivos jurídicos cujas coberturas são significativas e possíveis de serem mesuradas. Provavelmente por conta disso, não são contabilizadas as terras ocupadas por remanescentes das comunidades quilombolas.

A interpretação dada pelo Executivo brasileiro à definição de área protegida da $\mathrm{CDB}$, no âmbito desses relatórios, tem variado consideravelmente ao longo dos anos, inicialmente por conta de uma indefinição quanto ao enquadramento das terras indígenas, depois por conta da edição do PNAP, e, mais tarde, por conta da emergência da noção de outras medidas eficazes de conservação baseadas em áreas no âmbito das Metas de Aichi. Explicado em maior detalhe, inicialmente esses relatórios incluíam no cômputo das áreas protegidas brasileiras as unidades de conservação e as terras indígenas (BRASIL, 1998b, p. 66) ${ }^{15}$, mas, posteriormente, passaram a incluir apenas as unidades de conservação (BRASIL, 2004, p. 48-49, 2006d, p. 77-87). Com a promulgação do Decreto do PNAP, as terras indígenas voltaram a ser computadas (BRASIL, 2011, p. 67, 70). Mais recentemente, o relatório de $2016^{16}$ informa, ao tratar da Meta 11 de Aichi e das meta nacional correspondente, que o cálculo da superfície coberta por regimes protetivos passaria a incluir "outras áreas que também contribuem para a proteção da natureza, embora de forma diferenciada", nomeadamente "as áreas de preservação permanente e as reservas legais em propriedades privadas as terras indígenas que contenham vegetação nativa" (BRASIL, 2016, p. 114-115). A inclusão de dados relativos às áreas de preservação permanente e reservas legais seria possível por meio da implementação do Cadastro Ambiental Rural da Lei n. 12.651, de 25 de maio de 2012.

Assim, desde 2016 apenas as unidades de conservação têm sido computadas. Essa nova modificação do conteúdo atribuído ao conceito de área protegida deve ser compreendida à luz de duas questões. Primeiro, um "acordo tácito", entre a CDB e a UICN, de que

15 Note-se que no relatório de 1998 o termo "unidade de conservação" refere-se a uma diversidade de regimes jurídicos que foi parcialmente contemplada pela Lei do SNUC.

16 E, na mesma linha, o relatório de 2019. Vide a seção "National Target 11” em Brasil (2019a). 
suas noções de área protegida "são equivalentes" (LOPOUKHINE; DIAS, 2012, p. 5, trad. nossa), e a aprovação, pela UINC, de uma nova definição de área protegida, em 2008, salientando que os objetivos de conservação das áreas protegidas são prioritários, isso é, que eles constituam a finalidade primordial do regime jurídico da área protegida. E, em segundo lugar, essa questão responde à Decisão $\mathrm{X} / 2$ da $10^{\mathrm{a}} \mathrm{COP}$, que deu à Meta 11 de Aichi o seguinte conteúdo:

Até 2020 , ao menos $17 \%$ das áreas terrestres e de águas continentais, e $10 \%$ das zonas costeiras e áreas marinhas [...] estejam conservadas por meio de sistemas [...] de áreas protegidas e de outras medidas eficazes de conservação baseadas em áreas (CBD, 2011, p. 119, trad. nossa) ${ }^{17}$.

Não é o caso de tratar detalhar aqui o debate que se sucedeu à menção a essas “outras medidas", mas cabe apontar que ela levou a uma série de questionamentos a respeito de seu conteúdo e de sua relação com outros conceitos previamente reconhecidos no quadro da CDB. Temia-se que esse conceito fosse interpretado de maneira a permitir incluir, nos cálculos nacionais de superfícies protegidas, instrumentos que contribuem apenas vagamente para a proteção da biodiversidade (JONAS etal., 2017, p. 63-64; LOPOUKHINE; DIAS, 2012, p. 6). Esses questionamentos foram acompanhados de incursões buscando lançar luz sobre seu conteúdo. Entre outras possibilidades, foi sugerido que esse conceito teria sido introduzido como meio de dar reconhecimento a iniciativas privadas de conservação ou que têm como foco tipos específicos de desenvolvimento sustentável, ou aos territórios e áreas governados por populações indígenas e comunidades locais (JONAS et al., 2014, p. 112-113). Para outros, enquanto as áreas protegidas têm como objetivo fundamental a conservação da biodiversidade, nas outras medidas eficazes de conservação baseadas em áreas esse objetivo seria secundário ou implementado como resultado de outros objetivos (MACKINNON et al., 2015, p. 3559-3581). Essas proposições foram contempladas pela $14^{\mathrm{a}} \mathrm{COP}$ em 2018, que em sua decisão 14/8 adotou a seguinte definição de outra medida eficaz de conservação baseada em área:

Uma área geograficamente definida, que não é Área Protegida, que é governada e gerida de maneiras que alcançam resultados positivos e sustentáveis no longo prazo de conservação in situ da biodiversidade e de suas funções e serviços ecossistêmicos,

17 Essas "outras medidas eficazes de conservação baseadas em áreas" são chamadas "outras categorias de áreas oficialmente protegidas" pela Resolução CONABIO n. 06, de 3 de setembro de 2013 e pela Estratégia e Plano de Ação Nacionais para a Biodiversidade (BRASIL, 2017, p. 75, 90). 
e, onde aplicável, de valores culturais, espirituais, socioeconômicos e outros relevantes localmente $(\mathrm{CBD}, 2018, \S 2)$.

Essa noção, portanto, é definida em contraposição à noção de área protegida. Enquanto uma área protegida é "destinada, ou regulamentada" para conservar a biodiversidade, uma outra medida eficaz de conservação baseada em área é "governada e gerida de maneiras que alcançam resultados positivos e sustentáveis”. Essa distinção implica que nessas últimas a conservação da biodiversidade não constitui necessariamente seu objetivo principal, isso é, pode ser um objetivo secundário ou um resultado da realização de outros objetivos $^{18}$.

Em termos práticos, esse novo conceito permitiu ao governo brasileiro incluir em seus cálculos zonas que historicamente teve dificuldade em classificar como áreas protegidas da CDB, mas cuja extensão territorial não pode ser ignorada. Sua interpretação de que "as áreas de preservação permanente e as reservas legais em propriedades privadas e as terras indígenas que contenham vegetação nativa" constituem "outras áreas que também contribuem para a proteção da natureza, embora de forma diferenciada" vai ao encontro dos debates em torno desse novo conceito da $\mathrm{CDB}$ e da definição posteriormente adotada.

\subsubsection{Elementos para a superação da polissemia}

O conceito de área protegida da CDB é exclusivo, isso é, ele serve de parâmetro para que os Estados-partes identifiquem ou criem novos modelos jurídicos correspondentes em seus direitos internos. Contudo, seu uso no direito internacional atende a objetivos mais amplos e em contínua transformação. Por conta dessa mutabilidade dos objetivos da CDB, pode ser do interesse das Partes manterem relativamente flexíveis as relações entre os conceitos do direito internacional e seus conceitos do direito interno, e um dos artifícios que podem ser empregados nesses casos é a ambiguidade. Como se

18 A decisão $14 / 8$ da $14^{\text {a }}$ COP (CBD, 2018, § 9) convidou a UICN e outros organismos científicos a auxiliar as Partes na identificação de suas outras medidas eficazes de conservação baseadas em áreas. Um guia lançado pela UICN durante a $24^{\mathrm{a}}$ reunião do Corpo Subsidiário de Aconselhamento Científico, Técnico e Tecnológico da CDB afirma que o critério que distingue áreas protegidas de outras medidas eficazes de conservação baseadas em áreas é que as primeiras têm um "objetivo primário de conservação", ao passo que as segundas "realiza[m] a conservação in situ da biodiversidade, independentemente de seus objetivos" (IUCN, 2019, p. 3, trad. nossa) 
sabe, esse artifício possibilita ao legislador estender a pertinência da lei, pois, ao evitar definições inequívocas, pode permitir que seu texto regule objetos e situações passíveis de conhecerem modificações. A ambiguidade, portanto, é comum no direito e pode ser utilizado de maneira positiva (DÉAL, 2004, p. 247).

Em vista disso, uma análise do texto do PNAP sugere que sua ambiguidade possa ser proposital. Essa constatação é reforçada pelo documento publicado pelo proponente desse plano, o Ministério do Meio Ambiente, que, embora trate das unidades de conservação, terras indígenas e terras ocupadas por remanescentes das comunidades dos quilombos como sendo áreas protegidas, jamais o faz de maneira taxativa, preferindo dizer que o decreto "enfoca prioritariamente" esses dispositivos jurídicos. Essa última questão, em particular, parece ter sido reconhecida por parte da literatura especializada (LEUZINGER, 2007, p. 122).

Como consequência da ausência de uma definição precisa, as disposições do PNAP relativas às áreas protegidas devem ser consideradas à luz de desdobramentos posteriores no âmbito da $\mathrm{CDB}$, notadamente a emergência do conceito de outras medidas eficazes de conservação baseadas em áreas ou "outras categorias de áreas oficialmente protegidas" (BRASIL, 2013a, 2017, p. 75, 90), que permite sejam considerados e valorizados outros instrumentos de conservação in situ que contribuem à sua maneira para os objetivos da convenção, embora não constituam áreas protegidas.

Esse é justamente o caso das terras indígenas, terras ocupadas por remanescentes das comunidades dos quilombos, reservas legais e áreas de preservação permanente do direito brasileiro, que, embora desempenhem papel evidente na conservação da biodiversidade, o fazem de maneira indireta, subordinada a outros valores e objetivos: a proteção do quadro de vida das populações indígenas e quilombolas, a produção florestal sustentada e a estabilidade geológica e dos recursos hídricos. As reservas legais e áreas de preservação permanente, além do mais, não contam com uma gestão ativa equivalente às das áreas protegidas. Essa interpretação vai ao encontro do que estabelece o Decreto n. 8.505, de 20 de agosto de 2015, modificado pelo Decreto n. 10.140 , de 28 de novembro de 2019, relativos ao Programa Áreas Protegidas da Amazônia. Esse programa, que concerne a região amazônica, concerne apenas as unidades de conservação da Lei do SNUC, federais e estaduais. 
Tendo sido analisados o conteúdo e os usos do conceito de área protegida da $\mathrm{CDB}$, cabe tratar do conceito de área protegida da UICN, buscando identificar seu escopo em relação aos instrumentos de conservação in situ e seu interesse. Como se mostrará, esse conceito representa o consenso científico a respeito a respeito do que realmente importa para que uma área protegida seja efetiva, e, consequentemente, permite estabelecer relações de equivalência funcional entre regimes jurídicos de diferentes ordenamentos, e, consequentemente, conhecer o direito por meio de comparações.

\section{O CONCEITO DE ÁREA PROTEGIDA DA UNIÃO INTERNACIONAL PARA A CONSERVAÇÃO DA NATUREZA}

Amplamente citado mas raramente explicado em relação à sua finalidade, o conceito de área protegida da União Internacional para a Conservação da Natureza, assim chamado em referência à instituição que o elaborou e mantém atualizado ${ }^{19}$, foi concebido no contexto da rápida internacionalização do conservacionismo, e, mais precisamente, como resposta à difusão dos modelos jurídicos de proteção dos espaços naturais.

A crescente dificuldade em estabelecer uma terminologia e critérios capazes de compreender a diversidade de variações que esses modelos passaram a apresentar, quando de sua recepção pelos direitos nacionais, é fenômeno que possui implicações práticas importantes, sobretudo em vista de a proteção do ambiente natural demandar esforços conjuntos e complementares dos atores da comunidade internacional. Ela tem sido notada desde pelo menos a primeira metade do século $\mathrm{XX}$, mas a ideia de criação de um quadro conceitual transnacional apenas ganhou impulso após a Segunda Guerra Mundial, com a emergência de organismos intergovernamentais e de organizações conservacionistas de

19 Essa entidade foi criada por iniciativa da UNESCO e de uma vintena de governos nacionais. À época de sua criação, esses governos optaram por cria-la como um organismo de direito privado - e não como parte das Nações Unidas, como inicialmente previsto - pois essa condição lhe daria maior independência em relação aos governos nacionais. Sua natureza jurídica tem sido definida como sui generis, mas de fato trata-se de uma das primeiras organizações não governamentais organizadas por governos. A UICN reúne em suas comissões milhares de especialistas em conservação, e ao longo de sua história tem desempenhado um papel proeminente no assessoramento técnico de governos nacionais e organismos internacionais e na formação do direito ambiental. Sobre este último ponto, vide Olivier (2005), Robinson (2005) e Dillon (2004). 
amplitude mundial (PHILLIPS, 2004, p. 6). Esse rearranjo levou à necessidade de critérios científicos (3.1) que, por meio de seu conteúdo (3.2), permitissem identificar instrumentos jurídicos equivalentes. Esses critérios, portanto, constituem um instrumento para conhecimento desses instrumentos e de seus resultados em uma perspectiva comparativa (3.3).

\subsection{Um conceito científico}

$\mathrm{O}$ conceito de área protegida da UICN foi elaborado como expressão dos estândares técnicos considerados mais adequados pela comunidade científica interessada nas políticas públicas conservação da natureza, e seu objetivo central é, ele mesmo, científico, isso é, permitir comparações e o tratamento de dados das áreas protegidas dos países. Seu conteúdo exprime conhecimentos de diversas disciplinas, entre as quais o direito, visto que parte da efetividade das áreas protegidas passa por arranjos jurídicos adequados, e também porque esse conteúdo foi elaborado de maneira a compreender uma diversidade de elementos presentes em regimes jurídicos de conservação in situ dos direitos nacionais.

O prestígio científico do conceito de área protegida e do Sistema de Categorias de Gestão que o acompanha tem sido reconhecido em um número de ocasiões que cabem ser mencionadas. Primeiro, durante a $7^{\mathrm{a}} \mathrm{COP}$ da $\mathrm{CDB}$ os Estados-partes reconheceram "o valor de um único sistema internacional de classificação de áreas protegidas e os benefícios da produção de informação comparáveis através dos países e regiões", e, felicitando os esforços da UICN em refina-lo, encorajaram os governos nacionais e demais interessados a utiliza-lo (CBD, 2004, decisão VII/28, § 31, trad. nossa). Depois, os critérios da UICN são utilizados na elaboração da Lista de Áreas Protegidas das Nações Unidas e na Base de Dados Mundial de Áreas Protegidas (DEGUIGNET et al., 2014, p. 3; DUDLEY; STOLTON, 2008, p. 21), e têm conhecido uma utilização significativa no plano legislativo e na formulação de políticas públicas (BISHOP et al., 2004, p. 55-79). O prestígio científico com que esses padrões técnicos se revestem é determinante para seu crescente uso, e autoriza caracterizá-los como parte daquilo que a doutrina tem definido como soft law (DUPUY, 1990). 


\subsection{Conteúdo no direito brasileiro}

As origens do conceito de área protegida da UICN podem ser traçadas até a noção de "parques nacionais e reservas equivalentes", mencionada nos anos 1950 em uma decisão do Conselho Econômico e Social das Nações Unidas, que as identificou como importantes para o uso racional dos recursos naturais (PHILLIPS, 2004, p. 12, trad. nossa). Essa decisão foi endossada pela $17^{\mathrm{a}}$ Assembleia Geral das Nações Unidas, que confiou à UICN a tarefa de recensear essas zonas $^{20}$ (OLIVIER, 2005, p. 154). Esse levantamento confrontou seus autores com a necessidade de critérios apropriados (PHILLIPS, 2004, p. 4-14).

Embora não caiba detalhar aqui seu processo de elaboração, cumpre notar que seu conteúdo variou ao longo do tempo. Em 1969 a UICN adotou uma definição de parque nacional (IUCN, 1970, p. 22, 156), e pouco depois decidiu abandonar esse termo, "sobrecarregado de conotações emocionais e definições legais de âmbito nacional", em proveito de área protegida (DASMANN, 1974, p. 390-391, trad. nossa). Uma nova definição viu o dia em 1994 (IUCN-CNPPA; UNEP-WCMC, 1994, p. 7) e foi modificada substancialmente em 2008. Em todos os casos, essas modificações resultaram de processos compreensivos de consultas e discussões envolvendo governos nacionais e a comunidade científica, de modo a reunir consenso. Desde 2008 uma área protegida da UICN é definida como:

Um espaço geográfico claramente definido, reconhecido, dedicado e gerido, através de meios jurídicos ou outros igualmente eficazes, para obter a conservação a longo prazo da natureza, com os serviços ecossistêmicos e os valores culturais associados (DUDLEY, 2008, p. 8, trad. nossa).

Esse conceito busca dar conta da diversidade de variáveis presentes nos diferentes direitos, e a identificação das áreas protegidas se dá por meio de sua aplicação a seus objetivos de gestão (seus regimes jurídicos), e não a suas situações de fato (MCNEELY, 1993, p. 49; IUCN-CNPPA; UNEP-WCMC, 1994, p. 8; DUDLEY; STOLTON, 2008, p. 10). Interpretados à luz do direito brasileiro ${ }^{21}$,

20 Esse recenseamento daria origem à Lista de Áreas Protegidas das Nações Unidas (PHILLIPS, 2004, p. 12).

21 Como essa definição foi elaborada para ser aplicada em todo o mundo, ela inclui possibilidades estranhas à realidade brasileira. Por exemplo, nos direitos consuetudinários ou nos quais o costume é uma fonte prevalente do direito, o reconhecimento de uma área protegida e a definição de seus objetivos podem se dar por esse meio. 
esses critérios são a afetação individual da zona em questão, por meio de um ato do Poder Público que especifica seus limites específicos; a conservação da biodiversidade como objetivo fundamental; uma gestão ativa buscando dar efetividade a esse objetivo; e um regime jurídico que estabelece sansões e a perenidade da afetação. ${ }^{22}$

A análise desses elementos permite constatar que, no direito brasileiro, somente as unidades de conservação da natureza, da Lei n. 9.985, de julho de 2000, são áreas protegidas no sentido atribuído a esse termo pela UICN. Essa constatação vai ao encontro de ao menos uma fonte que tratou dessa questão (SANTILLI, 2005, p. 7881) e do uso técnico do termo unidade de conservação no Brasil (GANEM; ARAÚJO, 2006, p. 73).

Isso equivale a dizer que, por uma razão ou por outra, os outros dispositivos jurídicos brasileiros de conservação in situ não se enquadram nesse conceito. Esse é o caso, por exemplo, das terras indígenas e terras ocupadas por remanescentes das comunidades dos quilombos, por razões já mencionadas, e das reservas legais e áreas de preservação permanente, que, além do mais, não são afetadas individualmente e por ato específico. $\mathrm{O}$ mesmo se aplica às reservas da biosfera, que, embora sejam reconhecidas, não protegem por si mesmas as zonas sobre as quais incidem e, portanto, por si não proporcionam meios eficazes ou permitem obter a conservação.

A aplicação do conteúdo desse conceito aos instrumentos do direito brasileiro permite vislumbrar seu uso científico que interessa a este trabalho, isso é, enquanto instrumento metodológico do direito comparado. Como os elementos presentes na definição de área protegida da UICN possibilitam selecionar instrumentos jurídicos que são concebidos para responder a um mesmo conjunto de problemas específicos, eles permitem identificar instrumentos jurídicos que desempenham um papel equivalente em seus respectivos ordenamentos jurídicos, independentemente de suas nomenclaturas e do contexto em que se encontram, e que, portanto, apresentam equivalência funcional. Posto de maneira diferente, esse conceito de área protegida permite operacionalizar comparações jurídicas pertinentes.

22 Esta análise considerou também os esclarecimentos apresentados por Dudley (2008, p. 8-9). 


\subsection{Um instrumento comparativo}

O conceito de área protegida da UICN foi desenvolvido com o objetivo manifesto de permitir comparações ${ }^{23} \mathrm{e}$, conquanto os limites e possibilidades do método comparativo excedam os limites deste trabalho, a compreensão de seu interesse e das condições para sua utilização impõe explicitar seu lugar em pesquisas enquadradas por esse método.

A vertente mais difundida do método do direito comparado, dita funcionalista, toma a forma de um conjunto de postulados que permite realizar "a construção de relações de semelhança e dessemelhança entre diferentes questões de fato" e, como consequência dessas construções, conhecer os comparanda, isso é, os direitos comparados (JANSEN, 2008, p. 339, trad. nossa). Sua preocupação com questões de fato resulta da observação de que institutos semelhantes (instituições, regras, dispositivos e ferramentas jurídicas, entre outros) frequentemente apresentam diferenças fundamentais quanto a seus objetivos e aos papéis que desempenham em seus respectivos ordenamentos. Em outras palavras, institutos jurídicos semelhantes frequentemente desempenham funções distintas, e apenas questões de fato permitem identificar institutos jurídicos que apresentam equivalência funcional. ${ }^{24}$

Esse foco em questões de fato permite depreender alguns fundamentos e implicações da vertente funcionalista do método do direito comparado. Primeiramente, ela toma o direito a partir de sua relação funcional com a sociedade, isso é, se funda nas premissas de que o direito responde a necessidades e problemas humanos, de que os diferentes direitos tratam de necessidades e problemas semelhantes, e de que um mesmo problema ou necessidade pode conhecer respostas distintas nos diferentes direitos. Em segundo

23 Entre os motivos que orientaram a criação do conceito de área protegida e das categorias de gestão da UICN estão "reduzir a confusão que tem surgido da adoção de muitos termos para descrever diferentes tipos de áreas protegidas", "fornecer estândares internacionais para auxiliar cômputos regionais e comparações entre países", "fornecer um quadro para a coleta, tratamento e disseminação de informações", e "melhorar a comunicação [...] entre todos aqueles engajados na conservação" (IUCN-CNPPA; UNEP-WCMC, 1994, p. 5, trad. nossa).

24 Segundo Örücü $(2012$, p. 561, trad. nossa), a abordagem funcionalista do método do direito comparado "responde à questão 'Quais institutos no sistema B desempenham uma função equivalente à daquele em análise no sistema A?'. Da resposta dessa questão emerge o conceito de 'equivalência funcional'. Comparatistas buscam institutos que têm o mesmo papel, isso é, que têm 'comparabilidade funcional' ou resolvem um mesmo problema, isso é, 'similaridade de soluções"”. 
lugar, embora os objetos que se quer comparar não necessitem ser idênticos, eles carecem apresentar uma ou mais funções comuns para que sua comparação seja pertinente. Daí dizer que a comparabilidade desses objetos se confunde com seu tertium comparationis, seu denominador comum que, no âmbito da vertente funcionalista do método do direito comparado, corresponde à função ou ao conjunto de funções que os objetos jurídicos comparados compartilham (ÖRÜCÜ, 2012, p. 561). Por fim, uma outra consequência da vertente funcionalista do método do direito comparado é que potencialmente o tertium comparationis pode ser usado para avaliar os objetos comparados (MICHAELS, 2008, p. 342). Dito de outro modo, uma vez identificada a função em comum dos comparanda, ela pode ser usada para avaliar a efetividade com que cada um deles a realiza. Isso é particularmente aplicável quando os tertium comparationis são identificados externamente aos comparanda e tomam a forma de construções idealizadas.

O conceito de área protegida da UICN é exclusivo, isso é, somente os objetos que correspondem a cada uma de suas características podem ser considerados áreas protegidas no sentido que a UICN atribui ao termo. Como tal, ele reflete o que há em comum entre os objetos que não exclui, e pode servir como seu tertium comparationis. Adicionalmente, esse conceito expressa em sua definição um número mais amplo de funções do que aquele do conceito da $\mathrm{CDB}^{25}$, e, embora os comparanda devam apresentar ao menos uma função em comum para que sua comparação apresente alguma pertinência, é evidente que sua comparabilidade cresce à medida que mais funções são compartilhadas, isso é, ao passo que eles permitem tratar um número mais amplo de problemas ou necessidades comuns.

Além disso, como buscou-se mostrar, o conceito de área protegida da UICN foi elaborado como expressão dos estândares técnicos considerados mais adequados pela comunidade científica envolvida na conservação da natureza, e tendo em conta a diversidade de

$25 \mathrm{O}$ conceito de área protegida da CDB também é um tertium comparationis dos direitos nacionais, mas resulta de um processo político de negociação entre as Partes e não tão claramente do consenso científico a respeito dos problemas e necessidades das áreas protegidas. Depois, sua definição é pouco precisa e seu escopo em relação aos direitos internos frequentemente é objeto de definições oficiais, preocupadas mais os resultados da implementação da CDB do que com a comparabilidade dos instrumentos jurídicos utilizados com essa finalidade. Essencialmente, as comparações fundadas nesse conceito são pertinentes no quadro da própria CDB. 
características dos regimes jurídicos de proteção dos espaços naturais dos direitos nacionais. Disso se extrai, em primeiro lugar, que os elementos presentes na definição de área protegida da UICN são funções específicas identificadas pela comunidade científica como necessárias ao cumprimento da função geral a que se prestam as áreas protegidas. Dito de outro modo, as funções presentes nessa definição atendem a problemas e necessidades concretos que a comunidade científica, incluindo a comunidade jurídica, considera necessário serem tratados a fim de que as áreas protegidas cumpram seu papel. $\mathrm{E}$, em segundo lugar, isso permite inferir que os elementos presentes na definição de área protegida da UICN são tertium comparationis de boa parte dos regimes jurídicos nacionais de proteção dos territórios naturais. Como consequência dessa sua natureza dual, os dispositivos jurídicos que nele se enquadram compartilham funções jurídicas, isso é, respostas jurídicas a problemas concretos da conservação da natureza.

Enquanto tertium comparationis de instrumentos jurídicos de proteção das áreas naturais, o conceito de área protegida da UICN permite eliminar a arbitrariedade presente em pesquisas que concernem institutos cuja comparabilidade é apenas aparente. Isso não quer dizer, evidentemente, que sejam necessariamente arbitrárias as comparações que não fazem referência a esse conceito, pois diferentes objetivos de pesquisa implicam diferentes quadros comparativos e demonstrações da comparabilidade dos objetos escolhidos. Do mesmo modo, reconhecer que o conceito de área protegida da UICN permite identificar regimes jurídicos que cumprem funções em comum não equivale a dizer que o conceito de área protegida da UICN bastará a toda comparação. Embora ele permita identificar regimes jurídicos que compartilham uma diversidade de funções, dificilmente esses regimes jurídicos compartilharão todas as suas funções. Consequentemente, as próprias características da pesquisa empreendida devem determinar os requisitos metodológicos para sua pertinência, entre os quais o grau de comparabilidade entre os comparanda. Posto de outra maneira, dependendo do objeto e dos objetivos da pesquisa que se quer realizar, o conceito de área protegida da UICN pode servir tão somente como ponto de partida para que, a partir de outras funções, o pesquisador vá mais longe na identificação de regimes jurídicos que cumprem funções equivalentes. 


\section{CONSIDERAÇÕES FINAIS}

A utilização do termo "área protegida", no âmbito da literatura técnica e de decisões dos tribunais brasileiros, se caracteriza por um fenômeno de polissemia, isso é, a atribuição de uma pluralidade de significações a um mesmo significante. Essa constatação oferece uma oportunidade para que se busque identificar conceitos que contribuam para superar esse fenômeno, e este trabalho trata de dois conceitos que importam à comunidade que se interessa pelo direito e pelas políticas públicas de conservação da natureza: o conceito de área protegida da Convenção sobre Diversidade Biológica (CDB), que importa à atividade jurisdicional e à pesquisa em direito em sentido estrito, e o conceito de área protegida da União Internacional para a Conservação da Natureza (UICN), que permite estabelecer relações de equivalência funcional entre instrumentos jurídicos de diferentes ordenamentos, e, consequentemente, conhecê-los a partir de uma perspectiva comparativa.

Com relação ao conceito de área protegida da $\mathrm{CDB}$, buscouse demonstrar que o conteúdo atribuído a ele tem variado ao longo do tempo e em função de desdobramentos no direito brasileiro e no direito internacional. Em particular, este trabalho inova ao introduzir o debate a respeito do conceito de outras medidas eficazes de conservação baseadas em áreas, originário da Meta n. 11 de Aichi, cujo conteúdo tem sido estabelecido em contraposição ao de área protegida. Em particular, mostrou-se que, enquanto a conservação da biodiversidade constitui o objetivo fundamental de uma área protegida, nas outras medidas eficazes de conservação baseadas em áreas a conservação da biodiversidade constitui um objetivo indireto ou que resulta da realização de outros objetivos. Como consequência disso, a interpretação do governo brasileiro junto à $\mathrm{CDB}$ tem entendido, corretamente, que apenas as unidades de conservação da Lei n. 9.985, de julho de 2000 constituem áreas protegidas no âmbito da CDB.

Quanto ao conceito de área protegida da UICN, em um primeiro momento buscou-se apresentá-lo e salientar seu aspecto científico, para em seguida tratar de seu conteúdo e de sua correspondência no direito brasileiro. Este trabalho inova ao detalhar o papel que esse conceito pode desempenhar na pesquisa comparativa, isso 
é, enquanto instrumento metodológico que permite identificar e comparar regimes jurídicos funcionalmente equivalentes. Em detalhe, mostrou-se que os regimes jurídicos que se enquadram na definição de área protegida da UICN compartilham funções jurídicas, isso é, respostas dos direitos a problemas concretos. Enquanto tertium comparationis de regimes jurídicos nacionais de proteção das áreas naturais, esse conceito permite eliminar a arbitrariedade presente em pesquisas que concernem institutos cuja comparabilidade é apenas aparente.

\section{REFERÊNCIAS}

ABI-EÇAB, P. C. Principais ameaças ao meio ambiente em terras indígenas. Planeta Amazônia, Macapá, v. 3, p. 1-17, 2011.

ASSUNÇÃO, L. O. Unidades de conservação, terras indígenas e quilombolas no estado do Amapá: como desenvolver um estado cujo território está 70\% protegido por leis? Revista Brasileira de Políticas Públicas, Brasília, DF, v. 6, n. 3, p. 290-309, 2016.

BAJČIĆ, M. Terms, concepts and other conundrums. In: BAJČIĆ, M. New Insights into the Semantics of Legal Concepts and the Legal Dictionary. Amsterdam: John Benjamins, 2017. p. 7-26.

BARRAUD, B. La science et la doctrine juridiques à l'épreuve de la polysémie des concepts. Revue Interdisciplinaire d'Etudes Juridiques, Bruxelles, v. 76, p. 5-47, 2016.

BISHOP, K. et al. (ed.). Speaking a Common Language: Uses and performance of the IUCN System of Management Categories for Protected Areas. Cardiff: Cardiff University; IUCN; UNEP-WCMC, 2004.

BOYD, D. R. The constitutional right to a healthy environment. Environment: Science and Policy for Sustainable Development, Washington, v. 54, n. 4, p. 3-15, 2012.

BRAGA, A. S.; DELLA NINA, R. I. Áreas protegidas: mudança de paradigma no contexto das alterações climáticas? In: LEUZINGER, M. D.; TELES DA SILVA, S.; CUREAU, S. (orgs.). Espaços territoriais especialmente protegidos: extensão, limites e 
oportunidades. Brasília, DF: UniCEUB, 2015. p. 165-178.

BRASIL. Decreto n. 2.519, de 16 de março de 1998. Promulga a Convenção sobre Diversidade Biológica, assinada no Rio de Janeiro, em 5 de junho de 1992. Diário Oficial da União: seção 1, Brasília, DF, p. 1, 17 de março de 1998a.

BRASIL. Ministério do Meio Ambiente. Primeiro Relatório Nacional para a Convenção sobre Diversidade Biológica: Brasil. Brasília, DF: MMA, 1998 b.

BRASIL. Ministério do Meio Ambiente. Diretoria do Programa Nacional de Conservação da Biodiversidade. Segundo Relatório Nacional para a Convenção sobre Diversidade Biológica: Brasil. Brasília, DF: MMA, 2004.

BRASIL. CONABIO. Resolução CONABIO n. 03, de 21 de dezembro de 2006. Dispõe sobre as Metas Nacionais de Biodiversidade para 2010. Brasília, DF: MMA, 2006a. Disponível em: https://www. mma.gov.br/biodiversidade/comissao-nacional-de-biodiversidade/ resolucoes. Acesso em: 1 mar. 2019.

BRASIL. Ministério do Meio Ambiente. Secretaria de Biodiversidade e Florestas. Diretoria de Áreas Protegidas. Plano Estratégico Nacional de Áreas Protegidas - PNAP: Decreto n. 5.758, de 13 de abril de 2006. Brasília, DF: MMA, 2006b.

BRASIL. Decreto n. 5.758, de 13 de abril de 2006. Institui o Plano Estratégico Nacional de Áreas Protegidas - PNAP, seus princípios, diretrizes, objetivos e estratégias. Diário Oficial da União: seção 1, Brasília, DF, p. 1, 17 de abril de 2006c.

BRASIL. Ministério do Meio Ambiente. Secretaria de Biodiversidade e Florestas. Terceiro Relatório Nacional para a Convenção sobre Diversidade Biológica. Brasília, DF: MMA, 2006d.

BRASIL. Superior Tribunal de Justiça (2 $2^{\text {a }}$ Turma). Recurso especial n. 1.071.741-SP (2008/0146043-5). Recorrente: Min. Púb. SP. Recorridos: Fazenda do Estado de São Paulo e outros. Relator: Min. Herman Benjamin., 24 mar. 2009. Disponível em: https://ww2.stj. jus.br/processo/revista/. Acesso em: 19 fev. 2020.

BRASIL. Ministério do Meio Ambiente. Quarto Relatório Nacional 
para a Convenção sobre Diversidade Biológica: Brasil. Brasília, DF: MMA, 2011.

BRASIL. CONABIO. Resolução CONABIO n. 06, de 3 de setembro de 2013. Dispõe sobre as Metas Nacionais de Biodiversidade para 2020. Brasília, DF: MMA, 2013a. Disponível em: https://www. mma.gov.br/biodiversidade/comissao-nacional-de-biodiversidade/ resolucoes. Acesso em: 1 mar. 2020.

BRASIL. Tribunal Regional Federal da $4^{\mathrm{a}}$ Região (2 ${ }^{\mathrm{a}}$ Seção). Embargos Infringentes $n$. 5000970-08.2011.404.7007/PR. Embargante: Min. Púb. Fed. Embargado: Agência Nacional de Águas e outros. Relator: Cândido Alfredo Silva Leal Junior, 14 nov. 2013b. Disponível em: https://jurisprudencia.trf4.jus.br/pesquisa/ pesquisa.php. Acesso em: 27 fev. 2020.

BRASIL. Superior Tribunal de Justiça (2 ${ }^{\mathrm{a}}$ Turma). Recurso Especial n. 1406139-CE (2013/0325756-4). Recorrente: Min. Púb. Federal. Recorrido: F. C. de Souza. Relator: Min. Herman Benjamin, 5 ago. 2014. Disponível em: https://ww2.stj.jus.br/processo/revista/. Acesso em: 19 fev. 2020.

BRASIL. Ministério do Meio Ambiente. $5^{\circ}$ Relatório Nacional para a Convenção sobre Diversidade Biológica. Brasília, DF: MMA, 2016.

BRASIL. Ministério do Meio Ambiente. Estratégia e Plano de Ação Nacionais para a Biodiversidade - EPANB: 2016-2020. Brasília, DF: MMA, 2017.

BRASIL. Superior Tribunal de Justiça ( $5^{\text {a }}$ Turma). Agravo Regimental em Recurso Especial n. 1675032 / RJ (2017/0131655-5). Agravantes: P. J. Fontanezi e L. R. A. Souza. Agravado: Min. Púb. Federal. Relator: Min. Jorge Mussi, 25 set. 2018. Disponível em: https://ww2.stj.jus.br/processo/revista/. Acesso em: 19 fev. 2020.

BRASIL. Ministério do Meio Ambiente. Brazil: 6th National Report to the Convention on Biological Diversity. Brasília, DF: MMA, $2019 \mathrm{a}$.

BRASIL. Superior Tribunal de Justiça (2 $2^{\mathrm{a}}$ Turma). Agravo interno no agravo em recurso especial 1248039 - SP (2018/0033494-3). 
Agravante: Min. Púb. SP. Agravado: Cond. Resid. Ilha de Bali. Relator: Min. Francisco Falcão, 5 dez. 2019b. Disponível em: https:// ww2.stj.jus.br/processo/revista/. Acesso em: 19 fev. 2020.

BRITO, D. M. C. Conflitos em unidades de conservação. PRACS, Macapá, v. 1, n. 1, 2008.

BRUCK, E. C. et al. Unidades de conservação. Revista do Serviço Público, Brasília, DF, v. 40, n. 4, p. 21-27, 1983.

CBD. History of the Convention. Disponível em: https://www.cbd. int/history/. Acesso em: 10 fev. 2020.

CBD. COP 7. Decisions adopted by the Conference of the Parties to the Convention on Biological Diversity at its Seventh Meeting (UNEP/CBD/COP/7/21). CDB, 2004.

CBD. COP 10. Report of the Tenth Meeting of the Conference of the Parties to the Convention on Biological Diversity (UNEP/CBD/ COP/10/27). [s.1.]: CDB, 2011.

CBD. COP 14. Decision adopted by the Conference of the Parties to the Convention on Biological Diversity: 14/8. Protected areas and other effective area-based conservation measures (CBD/COP/ DEC/14/8). [s.1.]: CDB, 2018.

CORNU, G. Linguistique juridique. Paris: Montchrestien, 1990.

CRUZ, D. O. Desenvolvimento e Preservação em Espaços Especialmente Protegidos - Estudo de Caso Parque Estadual Gruta da Lagoa Azul em MT. Monografia (Especialidade em Direito Agroambiental e Sustentabilidade) - Universidade de Brasília, Cuiabá, 2015.

DASMANN, R. F. Development of a Classification System for Protected Natural and Cultural Areas. In: ELLIOT, H. (ed.). Second World Conference on National Parks, Morges: IUCN; National Parks Centennial Commission, 1974. v. II, p. 388-396.

DE KLEMM, C. Other International Developments. Environmental Policy and Law, [s.1.], vol. 9, n. 4, p. 117-128, 1982.

DE KLEMM, C.; SHINE, C. Biological Diversity Conservation and the Law: Legal Mechanisms for Conserving Species and Ecosystems. 
Gland; Cambridge: IUCN, 1993.

DÉAL, É. Langue du droit et doctrine : la linguistique juridique au service de l'accessibilité internationalisée des contributions doctrinales. Revue générale de droit, Sarbruque, v. 34, n. 2, p. 233265, 2004.

DEGUIGNET, M. et al. 2014 United Nations List of Protected Areas. Cambridge: UNEP-WCMC, 2014.

DIAS, R. B. et al. Cadastro ambiental rural como ferramenta de gestão do território, Planeta Amazônia, Macapá, v. 30, n. 3, p. 4755, 2018.

DILLON, B. The use of the categories in national and international legislation and policy. Parks, [s.1.], v. 14, n. 3, p. 15-22, 2004.

DISTRITO FEDERAL. Decreto n. 11.122, de 10 de junho de 1988, cria o Conselho Supervisor das Unidades de Conservação e Áreas Protegidas administradas pelo Distrito Federal. Diário Oficial do Distrito Federal: Brasília, DF, p. 4, 13 jun. 1988.

DUDLEY, N. (ed.). Guidelines for Applying Protected Area Management Categories. Gland: IUCN, 2008.

DUDLEY, N.; HAMILTON, L. Running Pure: Protected Areas Maintaining Purity and Quantity of Urban Water Supplies. In: DUDLEY, N.; STOLTON, S. (ed.). Arguments for protected areas. London: Earthscan, 2010. p. 39-52.

DUDLEY, N.; STOLTON, S. (ed.). Defining protected areas: an international conference in Almeria, Spain, May 2007. Gland: IUCN, 2008.

DUPUY, P.-M. Soft Law and the International Law of the Environment. Michigan Journal of International Law, Ann Arbor, v. 12, n. 2, p. 420-435, 1990.

FERREIRA, M.; VALERA, F. P. Instituições ligadas à conservação genética "in situ". Revista IPEF (atual Scientia Forestalis), Piracicaba, n. 35, p. 21-27, 1987.

FIGUEIREDO, M. F. As Reservas da Biosfera no Brasil. In: PORTANOVA, R. S.; LEITE, A. O.; FIGUEIREDO, M. F. (ed.). 
Os 15 anos da Lei n. 9.985, de 18 de julho de 2000: Anais do II Congresso de Direito Ambiental das Areas Protegidas. São Paulo: Ixtlan, 2015. p. 76-107.

GANEM, R. S.; ARAÚJO, S. V. G. DE. Reflexões acerca do conceito de espaços territoriais especialmente protegidos. Cadernos ASLEGIS, Brasília, DF, v. 8, n. 28, p. 63-82, 2006.

GILlESPIE, A. Definitions. In: GILLESPIE, A. Protected Areas and International Environmental Law. Leiden; Boston: Martinus Nijhoff, 2007. p. 27-46.

GINSBURG, T.; STEPHANOPOULOS, N. The Concepts of Law. The University of Chicago Law Review, Chicago, v. 84, n. 1, p. 147$175,2017$.

GUSMÃO CÂMARA, I. O papel das organizações não governamentais no cenário ambiental brasileiro, Revista da Escola Superior de Guerra, Rio de Janeiro, n. 17, p. 69-77, 1991.

GUTTERIDGE, H. C. The Comparative Aspects of Legal Terminology. Tulsane Law Review, Nova Orleães, v. 12, p. 401-411, 1938.

IUCN. Tenth General Assembly: Vigyan Bhavan, New Delhi, 24 November - 1 December, 1969. Morges: IUCN; Unesco, 1970. (Proceedings and Summary of Business, v. II).

IUCN. WCPA Task Force on OECMs. Recognising and reporting other effective area-based conservation measures. Gland: IUCN, 2019.

IUCN-CNPPA; UNEP-WCMC. Guidelines for Protected Area Management Categories. Gland; Cambridge: IUCN, 1994.

JANSEN, N. Comparative Law and Comparative Knowledge. In: REIMANN, M.; ZIMMERMAN, R. (ed.). The Oxford Handbook of Comparative Law. Nova Iorque: Oxford University Press, 2008. p. 305-337.

JÉGOUZO, Y. Existe-t-il un territoire pertinent ? In: FOUCHER, K.; ROMI, R. (org.). La décentralisation de l'environnement : territoires et gouvernance. Aix-en-Provence: PUAM, 2006, p. 121-126. 
JONAS, H. et al. New Steps of Change: Looking Beyond Protected Areas to Consider Other Effective Area-Based Conservation Measures. Parks, [s.1.], v. 20, n. 2, p. 111-128, 2014.

JONAS, $\mathrm{H}$. et al. Will "other effective area-based conservation measures" increase recognition and support for ICCAs? Parks, [s.1.], v. 23, n. 2, p. 63-78, 2017.

KEENLEYSIDE, $\mathrm{K}$. et al. Realizing the potential of protected areas as natural solutions for climate change adaptation. Parks, [s.l.], v. 20, n. 1, p. 67-78, mar. 2014.

LEUZINGER, M. D. Natureza e cultura: direito ao meio ambiente equilibrado e direitos culturais diante da criação de unidades de conservação de proteção integral e domínio público habitadas por populações tradicionais. Tese (Doutorado em Desenvolvimento Sustentável) - Universidade de Brasília, Brasília, DF, 2007.

LOPOUKHINE, N.; DIAS, B. F. S. Editorial: What Does Target 11 Really Mean? Parks, [s.1.], v. 18, n. 1, p. 5-8, 2012.

MACKINNON, D. et al. Canada and Aichi Biodiversity Target 11. Biodiversity and Conservation, [s.1.], v. 24, n. 14, p. 3559-3581, dez. 2015.

MAGNANINI, A. O pinheiro brasileiro, a ecologia e a necessidade de uma reserva biológica. Floresta, Curitiba, v. 3, n. 1, p. 17-20, 1971.

MCNEELY, J. A. (ed.). Parks for Life: Report of the IVth World Congress on National Parks and Protected Areas, 10-21 February 1992. Gland: IUCN, 1993.

MEDEIROS, R.; IRVING, M.; GARAY, I. A proteção da natureza no Brasil: Evolução e conflitos de um modelo em construção. Revista de Desenvolvimento Econômico, Salvador, v. 6, n. 9, p. 83-93, 2004.

MICHAELS, R. The Functional Method of Comparative Law. In: REIMANN, M.; ZIMMERMAN, R. (ed.). The Oxford Handbook of Comparative Law. Nova Iorque: Oxford University Press, 2008. p. 339-382.

OLIVEIRA, L. J. D. Regularização fundiária de unidades de conservação. Boletim Científico ESMPU, Brasília, DF, v. 9, n. 32/33, p. 143-176, 2010. 
OLIVIER, J. Le rôle de l'UICN dans la formation du droit de l'environnement. In: OLIVIER, J. L'Union mondiale pour la nature (UICN): une organisation singulière au service du droit de l'environnement. Bruxelas: Bruylant, 2005. p. 149-222.

ÖRÜCÜ, E. Methodology of Comparative Law. In: SMITS, J. M. (ed.). Elgar Encyclopedia of Comparative Law. 2. ed. Cheltenham: Edward Elgar Publishing, 2012. p. 560-576.

PARÁ. Tribunal de Justiça (1 ${ }^{\text {a }}$ Câmara Civel Isolada). Agravo de instrumento, n. 2012.3.003780-1. Agravante: F. W. P. de Souza. Agravado: Ponte Participações Ltda. Relator: Des. Marneide T. P. Merabet. Diário da Justiça do Estado do Pará, ed. 5285, Belém, p. 57, 17 de junho de 2013.

PEREIRA, P. F.; SCARDUA, F. P. Espaços territoriais especialmente protegidos: conceito e implicações jurídicas. Ambiente \& Sociedade, São Paulo. v. XI, n. 1, p. 81-97, 2008.

PHILLIPS, A. The history of the international system of protected area management categories. Parks, [s.1.], v. 14, n. 3, p. 4-14, 2004.

PRATES, A. P. L.; IRVING, M. DEA. Conservação da biodiversidade e políticas públicas para as áreas protegidas no Brasil: desafios e tendências da origem da CDB às metas de Aichi. Revista Brasileira de Políticas Públicas, Brasília, DF, v. 5, n. 1, p. 27-57, 14 jun. 2015.

RIO DE JANEIRO. Tribunal de Justiça (10ª Câm. Cível). Agravo de instrumento 0024449-90.2018.8.19.0000. Agravante: A. A. Rocha. Agravado: Mun. Angra dos Reis. Relator: Des. José Carlos Varanda dos Santos, 21 ago. 2019. Disponível em: http://www4.tjrj.jus.br/ ejuris/ConsultarJurisprudencia.aspx. Acesso em: 19 fev. 2020

RIOS, A. V. V. Populações tradicionais em áreas protegidas. In: RICARDO, F. (ed.). Terras Indígenas \& Unidades de Conservação da natureza: o desafio das sobreposições. São Paulo: Instituto Socioambiental, 2004. p. 78-84.

ROBINSON, N. A. IUCN as Catalyst for a Law of the Biosphere: Acting Globally and Locally. Environmental Law, Portland, n. 249, 2005.

RODARY, E.; MILIAN, J. Extension et diversification des aires 
protégées : rupture ou continuité ? In: AUBERTIN, C.; RODARY, E. (ed.). Aires protégées: espaces durables? Marseille: IRD, 2008. p. 33-54.

SADELEER, N. DE. La protection de la nature et de la biodiversité. In: PETIT, Y. (ed.). Droit et politiques de l'environnement. Paris: La documentation Française, 2009. p. 187-199.

SANTILLI, J. A lei 9.985/2000, que instituiu o sistema nacional de unidades de conservação da natureza (SNUC): uma abordagem socioambiental. Revista de Direito Ambiental, São Paulo, v. 40, p. 78-110, out. 2005.

SÃO PAULO. Tribunal de Justiça ( $1^{\text {a }}$ Câm. Res. Meio Ambiente). Apelação cível n. AC 0000980-58.2010.8.26.0563 (n. reg. 2019.0000604011). Apelante: S.E.R.R.A Sociedade Pro educação. Apelados: J. E. P. Gerevini e L. C. Gerevini. Relator: Des. Torres de Carvalho, 1 ago. 2019. Disponível em: https://esaj.tjsp.jus.br/. Acesso em: 19 fev. 2020

SÃO PAULO. Tribunal de Justiça ( $1^{\text {a }}$ Câm. Res. Meio Ambiente). Embargos infringentes n. 994.07.150004-3/50002. Embargante: Fazenda do Estado de São Paulo. Embargados: Prefeitura de São Paulo e outros. Relator: Des. Lineu Peinado, 18 fev. 2010. Disponível em: https://esaj.tjsp.jus.br/. Acesso em: 28 fev. 2020

SÃO PAULO. Tribunal de Justiça (2 ${ }^{\text {a }}$ Câm. Res. Meio Ambiente). Apelação cível n. 0001446-10.2011.8.26.0210. Apelante/apelado: Min. Púb. SP. Apelantes/apelados: Espolio de J. C. Ferreira e A. D. Ferreira Botelho. Relator: Des. Alvaro Passos, 18 jun. 2015. Disponível em: https://esaj.tjsp.jus.br/. Acesso em: 19 fev. 2020

SÃO PAULO. Tribunal de Justiça (2a Câm. Res. Meio Ambiente). Apelação em Ação Civil Pública, n. 00024550720118260210 (Registro 2016.0000890433). Apelantes: M. C. N. L. Nicoliello e outra. Apelado: Min. Púb. SP. Relator: Des. Roberto Maia, 1 dez. 2016. Disponível em: https://esaj.tjsp.jus.br/. Acesso em: 19 fev. 2020

SÃO PAULO. Tribunal de Justiça (2 $2^{\text {a }}$ Cam. Res. Meio Ambiente). Remessa Necessária n. 0002946-04.2014.8.26.0244. Recorrente: $2^{\text {a }}$ Vara de Iguape. Recorrido: Min. Pub. SP. Relator: Paulo Ayrosa, 
13 dez. 2018. Disponível em: https://esaj.tjsp.jus.br/. Acesso em: 19 fev. 2020

SOARES-FILHO, B. et al. Role of Brazilian Amazon protected areas in climate change mitigation. Proceedings of the National Academy of Sciences, [s.1.], v. 107, n. 24, p. 10821-10826, 26 maio 2010.

SOUZA, R.; LEAL, G. F.; MACIEL, F. M. Participação em áreas protegidas. Veredas do Direito, Belo Horizonte, v. 16, n. 35, p. 403$-426,2019$.

UNEP-WCMC; IUCN; NGS. Protected Planet Report 2018. Cambridge; Gland; Washington: UNEP-WCMC; IUCN, 2018.

Artigo recebido em: 17/03/2020. Artigo aceito em: 23/10/2020.

\section{Como citar este artigo (ABNT):}

LEITE, A. O. A polissemia do termo "área protegida" e os conceitos da CDB e da UICN. Veredas do Direito, Belo Horizonte, v. 17, n. 39, p. 207-241, set./dez. 2020. Disponível em: http://www.domhelder. edu.br/revista/index.php/veredas/article/view/1807. Acesso em: dia mês. ano. 